\title{
Deciphering congenital anomalies for the next generation
}

\author{
Monica H. Wojcik and Pankaj B. Agrawal \\ Divisions of Newborn Medicine and Genetics and Genomics, Department of Pediatrics, The Manton Center \\ for Orphan Disease Research, Boston Children's Hospital and Harvard Medical School, Boston, Massachusetts \\ 02115, USA
}

\begin{abstract}
Congenital anomalies are common, with $2 \%-3 \%$ of infants estimated to have at least one major congenital malformation and countless others with minor malformations of lesser cosmetic or medical importance. As congenital malformations are major drivers of morbidity and mortality, representing the leading cause of infant mortality in the United States, there is substantial interest in understanding the underlying etiologies-particularly if modifiable causes may be identified or pre- or postnatal treatments can be offered. Recent research has begun to reveal the spectrum of monogenic disorders that commonly result in birth defects, and newer approaches have revealed non-Mendelian genetic contributions including gene-environment interactions. Our experience suggests that increased efforts to sequence and analyze cases of perinatal death, as well as continued global collaboration, will be essential in understanding the genomic landscape of structural anomalies.
\end{abstract}

Corresponding author: monica.wojcik@childrens .harvard.edu; pankaj.agrawal@ childrens.harvard.edu

(C) 2020 Wojcik and Agrawal This article is distributed under the terms of the Creative Commons Attribution-NonCommercial

License, which permits reuse and redistribution, except for commercial purposes, provided that the original author and source are credited.

Published by Cold Spring Harbor Laboratory Press

doi:10.1101/mcs.a005504

\section{INTRODUCTION}

Since the report more than 30 years ago by Nelson and Holmes surveying nearly 70,000 stillborn and live-born infants, which established the prevalence of major congenital anomalies in this population at $2 \%$ (Nelson and Holmes 1989), research into the epidemiology and etiology of these anomalies has continued to yield important new insights and reflects the evolution of genetic diagnostic technology. Advances in human genetics and genomics have redefined our understanding of many major structural anomalies occurring in isolation or as part of a syndrome, although the underlying molecular basis of several anomaliesfrom isolated congenital cardiac defects to commonly seen patterns of malformations such as VACTERL (vertebral defects, anal atresia, cardiac defects, tracheo-esophageal fistula, renal, and limb abnormalities)_remains poorly understood. Even within a well-defined genetic syndrome, such as Down or Patau syndrome, the variable presentations of structural anomalies remain a mystery (Springett et al. 2015; Stoll et al. 2015).

To further understand these anomalies, collecting detailed and accurate genotype and phenotype data from affected individuals and engaging in open and rich data-sharing initiatives are critically important. Although each major congenital anomaly is individually rare, they are collectively more common and contribute disproportionately to the national and global morbidity and mortality burden (Arth et al. 2017; Boyle et al. 2018; Xu et al. 2020). Current efforts have revealed that many congenital anomalies occur in the context of an identifiable genomic variant, even if many variants remain cryptic to techniques such as chromosomal microarray and exome sequencing (Miller et al. 2010; Lord et al. 2019; Petrovski 
et al. 2019). As genomic technology continues to advance at a tremendous rate, optimizing the impact of new diagnostic techniques will require large-scale collaborations in order to make meaningful discoveries. Although pinpointing the genetic or genomic variants underlying structural anomalies remains challenging, our experience has shown that postmortem sequencing of perinatal deaths is particularly high yield for genetic diagnosis and gene discovery, despite the logistical difficulties. The genomic or molecular "autopsy" will be another key contributor to deciphering congenital anomalies.

\section{SURVEILLANCE FOR CONGENITAL ANOMALIES}

Many factors influence the prevalence of congenital anomalies in the general population. The point of ascertainment, as well as the method and even the definition of what constitutes a congenital anomaly, may substantially influence these calculations (Kirby 2017). For example, structural abnormalities are thought to affect $3 \%$ of pregnancies (Centers for Disease Control and Prevention 2008), 20\% of all pregnancy losses (Heinke et al. 2020), 8.5\% of stillbirths (fetal deaths after $20 \mathrm{wk}$ ) (Holmes et al. 2018), and 2.4\% of live-born infants (Nelson and Holmes 1989; Mai et al. 2019). Furthermore, public health policies may also influence both the prevalence and mortality rates associated with congenital anomalies, as countries that do not allow termination of a pregnancy because of congenital anomalies report higher rates of neonatal mortality caused by these conditions (Boyle et al. 2018).

Congenital anomalies may be detected by physical examination and/or imaging studies. As imaging techniques have improved, "technology-detected malformations" have been identified: asymptomatic structural anomalies that would be detected only by advanced imaging. These anomalies-nonsevere atrial septal defect or ventricular septal defect and patent ductus arteriosus (excluding those found in preterm infants that are physiologically normal)—have increased in prevalence over time compared to anomalies such as tetralogy of Fallot (Straub et al. 2019). As prenatal imaging techniques continue to improve, congenital anomalies may be more frequently identified even earlier in pregnancy. The genetic underpinnings of these more subtle anomalies, compared to severe malformations leading to fetal demise, may differ substantially. Including the entire spectrum in sequencing studies is critical, particularly as defining the full fetal phenotype of genetic syndromes associated with structural malformations is needed to interpret prenatal genetic testing results and for prenatal counseling (Gray et al. 2019).

Identifying cases for prospective studies can be achieved in various ways. Most studies focus on major congenital anomalies, or those of cosmetic or medical importance to the individual (Centers for Disease Control and Prevention 2015), though others may be more inclusive, particularly those using hospital billing or discharge codes, because of poor distinctions between categories of birth defects within the coding system (Holmes and Westgate 2012). In the United States, funding was established in 1996 for the National Birth Defects Prevention Study (NBDPS), which has collected data on nearly 45,000 cases of major congenital anomalies from 10 centers across the nation (Reefhuis et al. 2015). In addition to collecting data from medical records by trained abstractors, which is more accurate than using ICD codes (Holmes and Westgate 2012), the NBDPS interviews eligible families to identify potential contributing factors and has collected buccal swabs for genetic evaluation of the affected individual and parents for more than 20,000 participants (Reefhuis et al. 2015; Jenkins et al. 2019). The rich data produced by this study and other state-led birth defects surveillance programs (Centers for Disease Control and Prevention 2008) continue to inform birth defects research and have led to hundreds of publications in addition to discoveries of modifiable risk factors and public health interventions, such as the use of folic acid to prevent neural tube defects (Lin et al. 2009; Williams et al. 2015). However, these studies may 
be biased toward nonlethal phenotypes, which is important in interpreting their results (Heinke et al 2020).

\section{GENETIC CAUSES OF BIRTH DEFECTS}

In the landmark report by Nelson and Holmes, 205/1549 (13\%) infants with a major malformation had an identifiable genetic cause-either chromosomal $(157 / 1549,10 \%)$ or monogenic (48/1549, 3.1\%), although the underlying genes responsible for the monogenic disorders were poorly understood at the time (Nelson and Holmes 1989). In the 30 years since its publication, genes have been identified for all of the suspected monogenic conditions listed in this paper except Moebius syndrome (Nelson and Holmes 1989). The estimate of a monogenic condition underlying $3.1 \%$ of birth defects was made with full knowledge that there were likely other genetic causes of birth defects that had not yet been described (Nelson and Holmes 1989).

There are many different ways in which genomic variation can lead to congenital anomalies. Certain anomalies may be caused by Mendelian disorders, in which a disease-causing change at a single locus results in a spectrum of anomalies. Others may be related to genetic factors that are non-Mendelian. These include oligogenic disorders caused by variants in a few genes (Pehlivan et al. 2019); somatic pathogenic variants that occur in a specific tissue and would not be found across all cells of the body (Lim et al. 2015); single-nucleotide polymorphisms (SNPs) increasing the susceptibility to a particular condition; and epigenetic variants affecting the expression of certain genes (Hobbs et al. 2014). Currently, our ability to assess for Mendelian disorders in the clinical setting outweighs the ability to evaluate for nonMendelian causes of disease, although this is an active area of research (Boycott et al. 2019).

Estimates of the contribution of genetic disorders to structural anomalies must take into account the time point at which these anomalies are ascertained and the genomic technology used. As many structural anomalies lead to pregnancy loss or occur in pregnancies that are not continued (Heinke et al. 2020), the genetic landscape of birth defects in live-born infants may differ from that of infants who do not survive the pregnancy. The population described by Drs. Holmes and Nelson involved live- or stillborn infants and estimated that $\sim 13 \%$ of cases with structural anomalies were explainable by a genetic cause (Nelson and Holmes 1989), compared to the $37 \%-50 \%$ described in studies restricted to stillbirths with structural anomalies using exome sequencing (ES) (Vora et al. 2017; Shamseldin et al. 2018; Quinlan-Jones et al. 2019). The methodologies used to evaluate for genetic causes of birth defects must also be considered. Many structural anomalies occur as part of aneuploidy syndromes detectable by karyotype and chromosomal microarray, the latter of which has been shown to have a diagnostic yield of $6 \%$ of prenatal cases of structural anomalies (Wapner et al. 2012) and is commonly used clinically for prenatal diagnosis. Massively parallel sequencing technology is often used as the next step if microarray is unrevealing, particularly ES. Recently, two large studies using ES to evaluate pregnancies in which a fetal structural anomaly was detected found a diagnostic yield of $\sim 10 \%$, with the diagnostic yield increasing for fetuses with more than one anomaly (Lord et al. 2019; Petrovski et al. 2019). In the postnatal setting, ES has been used in many large cohorts focusing on a particular defect and identifying a diagnosis in $37.5 \%$ cases of craniosynostosis (Miller et al. 2017), 10\% for nonsyndromic oral clefts (Basha et al. 2018), and 14\% for congenital anomalies of the kidney or urinary tract (van der Ven et al. 2018). Postnatal cohort studies of critically ill infants undergoing ES for genetic diagnosis have found that congenital anomalies associated with genetic syndromes are often diagnosed using this technology (Meng et al. 2017; Gubbels et al. 2019). Genome sequencing, which has the potential to detect variants outside of the protein-coding regions covered by ES in addition to offering improved ability to detect 
structural variants and other types of variants undetectable by ES or gene panel testing, has also been used to evaluate for genetic causes of congenital anomalies. Although at this time, the ability to fully analyze and interpret data generated by genome sequencing remains incompletely understood (Lionel et al. 2018; Perenthaler et al. 2019), promising new research into the role of noncoding variants suggests this as an avenue for further research (Richter et al. 2020).

Certain structural malformations may be more indicative of an underlying Mendelian condition than others. Cardiac anomalies such as truncus arteriosus and interrupted aortic arch are known to be associated with 22q11 deletion syndrome, whereas others such as hypoplastic left heart syndrome are less often associated with a genetic syndrome (Li et al. 2017). Open neural tube defects and midline abdominal defects such as gastroschisis observed in isolation have also been low-yield in genomic sequencing studies (Ross et al. 2017; Salinas-Torres et al. 2020). Future research is likely to reveal genomic changes causing such apparently isolated anomalies. For example, one recent, large sequencing study of leftsided cardiac defects identified 27 candidate genes and found their cohort overall to be enriched for de novo loss of function variants (Li et al. 2017). When multiple anomalies occur together, an underlying genetic diagnosis is more likely to be found, as reflected in prior studies using ES for diagnosis (Lord et al. 2019; Petrovski et al. 2019; Gubbels et al. 2020). However, certain combinations seem to be more high-yield than others. The lack of unique facial features (possibly recognizable in the newborn period) or developmental disorders (not recognizable in the newborn period) may suggest that ES is more likely to be nondiagnostic. Although some recurrent constellations of anomalies have been successfully linked to a single gene, such as the spectrum seen in CHARGE syndrome (coloboma, heart defects, atresia choanae, retarded growth and development, genitourinary anomalies, ear anomalies), caused by pathogenic CHD7 variants, other associations such as VACTERL and OEIS (omphalocele, bladder exstrophy, imperforate anus, spinal defect) complexes are be less likely to have a Mendelian disorder identified, particularly if no other syndromic features are present (Meng et al. 2017). Why they continue to occur in combination remains a mystery.

Future studies are likely to further elucidate the complex genetic mechanisms at play in early embryogenesis when these structural anomalies arise, which may defy traditional Mendelian patterns of inheritance. Examples include the digenic inheritance of both a rare and more common variant causing craniosynostosis (Timberlake et al. 2016), somatic variants found to underlie a type of brain malformation that causes intractable epilepsy (Lim et al. 2015), and de novo noncoding variants recently implicated in congenital heart disease (Richter et al. 2020). The formation of consortiums such as the Centers for Mendelian Genomics (Bamshad et al. 2012; Posey et al. 2019), Care4Rare, and FORGE (Sawyer et al. 2016), the Undiagnosed Diseases Network (Ramoni et al. 2017), the Deciphering Developmental Disorders study (DDD Study et al. 2015), and the Gabriella Miller Kids First Pediatric Research Program (https://commonfund.nih.gov/kidsfirst/overview) with the resources to sequence thousands of individuals and share data in a collaborative analytic approach has transformed rare disease research and led to the identification of thousands of novel and candidate novel disease genes (Bamshad et al. 2019), many of which involve congenital anomalies.

\section{GENETIC SUSCEPTIBILITY AND ENVIRONMENTAL CAUSES OF BIRTH DEFECTS}

In addition to pathogenic genetic variation, many environmental exposures have been linked to major congenital anomalies, such as maternal diabetes (Nasri et al. 2018); maternal medications such as warfarin, phenytoin (Toufaily et al. 2018), and retinoic acid (Lammer 
et al. 1985); maternal conditions such as phenylketonuria (Lenke and Levy 1980); and other maternal exposures such as alcohol consumption or infection (Rasmussen et al 2016). Studies such as the NBDPS have attempted to focus on environmental or teratogenic causes of birth defects by excluding cases in which a monogenic or chromosomal disorder is present, as assessed by review of cases by clinical experts (Reefhuis et al. 2015). However, as genetic testing is not pursued for all cases of birth defects, and the most common test performed is chromosomal microarray (which has a relatively low yield, particularly for isolated congenital anomalies), certain cases included in the NBDPS or other surveillance programs may have monogenic causes that would be found by additional sequencing (Toufaily et al. 2018; Jenkins et al. 2019). Even in the absence of a monogenic cause, there is likely a complex interplay between these exposures and genetic risk factors that further studies are likely to address. Furthermore, genomic sequencing has identified critical pathways involved in the development of structural anomalies that may be amenable to environmental influence, such as the detection of pathogenic variants in the NAD synthesis pathway causing VACTERL association in multiple families that may be treatable by niacin supplementation (Shi et al. 2017). This report exemplifies the interaction between genomic sequencing data, functional evaluation with animal models, and correlation to environmental factors that made lead to targeted therapies. As ES has been successfully performed using DNA extracted from buccal swabs provided in the NBDPS (Jenkins et al. 2019), this represents an exciting opportunity to combine an analysis of genetic and environmental factors in a diverse and large data set to further understand the underlying mechanisms of structural anomalies.

\section{EXAMPLES OF MONOGENIC CAUSES OF CONGENITAL ANOMALIES FROM OUR INSTITUTION}

The following families were recruited to our Gene Discovery Core protocol within the Manton Center for Orphan Disease Research at Boston Children's Hospital. Informed consent was obtained via our Institutional Review Board-approved protocol. Trio exome sequencing was performed through the Broad Institute Center for Mendelian Genomics using methods as previously described (Wojcik et al. 2019).

1. A 15-mo-old boy was admitted to our institution for surgical management of mitral and tricuspid valve disease. He was born with an atrial septal defect in addition to the valvar abnormalities. The child was noted to have straight eyebrows, a depressed nasal root, micrognathia, and bilateral 3-4 syndactyly on examination by a clinical geneticist. Chromosomal microarray was not diagnostic, and DNA was obtained for ES, which was performed postmortem and revealed a missense variant in PRKD1 (c.2017G > C, p.Asp673His, ENST0000415220), confirmed to be de novo in the proband and classified as likely pathogenic by American College of Medical Genetics and Genomics (ACMG) criteria (Richards et al. 2015). This gene has been associated with syndromic cardiac disease (Sifrim et al. 2016), although the full phenotypic spectrum remains to be elucidated. Our case helps to define the phenotype of this rare disorder for patients, families, and providers looking for answers; this opportunity would have been lost if postmortem sequencing had not been performed.

2. A 4-mo-old preterm infant was admitted to the neonatal intensive care unit (NICU) at our institution for management of a congenital craniofacial anomaly. At delivery, she was noted to have fusion of her maxilla and mandible. Her jaw was manually separated in the delivery room and she was intubated and she ultimately required tracheostomy placement. Because of progressive narrowing of her oral opening attributed to gingival adhesions, she was transferred to our institution for a craniofacial evaluation and 
Competing Interest Statement

The authors have declared no competing interest. management of her congenital syngnathism. On examination by the clinical genetics team, she was also noted to have severe migrognathia and "question-mark" shaped ears. She died at 5 mo of age of an unrelated cause, and postmortem trio exome sequencing revealed a de novo missense variant in PCLB4 (c.1888G > A, p.Asp630Asn, ENST00000378501), classified as likely pathogenic by ACMG criteria, consistent with a diagnosis of auriculocondylar syndrome. This case highlights the challenges faced by children with this condition, as well as allowing counseling for the family on its recurrence risk.

\section{CONCLUSION AND FUTURE DIRECTIONS}

Although the last decade has seen impressive advances in our understanding of congenital anomalies and their causes, much remains to be understood. The collection and centralization of high-quality phenotypic data and collaborative sequencing efforts make this an exciting time for research into the causes of congenital anomalies. As genomic sequencing progresses and large data sets are generated for particular birth defects, pooling this data in a publicly available resource for researchers continues to be essential in order to maximize the benefit of these technologies. This coupled with detailed phenotyping and the ability to connect environmental and genetic factors will lead to further breakthroughs. The inclusion of perinatal deaths in these approaches will also be critical to inform our understanding of genomic variants resulting in structural anomalies as the full phenotypic spectrum of many disorders cannot be understood without sequencing these cases.

\section{ADDITIONAL INFORMATION}

\section{Acknowledgments}

The authors thank the patients that they work with on both a clinical and research basis for continuing to drive and inspire their work. We also thank Grace VanNoy for her contribution to the analysis of one of our case examples above.

\section{Funding}

M.H.W. is supported by UM1HG008900. P.B.A. is supported by R01 AR068429. Sequencing and analysis were provided by the Broad Institute of MIT and Harvard Center for Mendelian Genomics (Broad CMG) and were funded by the National Human Genome Research Institute, the National Eye Institute, and the National Heart, Lung, and Blood Institute grant UM1 HG008900 and in part by National Human Genome Research Institute grant R01 HG009141.

\section{REFERENCES}

Arth AC, Tinker SC, Simeone RM, Ailes EC, Cragan JD, Grosse SD. 2017. Inpatient hospitalization costs associated with birth defects among persons of all ages-United States, 2013. MMWR Morb Mortal Wkly Rep 66: 41-46. doi:10.15585/mmwr.mm6602a1

Bamshad MJ, Shendure JA, Valle D, Hamosh A, Lupski JR, Gibbs RA, Boerwinkle E, Lifton RP, Gerstein M, Gunel M, et al. 2012. The Centers for Mendelian Genomics: a new large-scale initiative to identify the genes underlying rare Mendelian conditions. Am J Med Genet A 158A: 1523-1525. doi:10.1002/ajmg .a.35470

Bamshad MJ, Nickerson DA, Chong JX. 2019. Mendelian gene discovery: fast and furious with no end in sight. Am J Hum Genet 105: 448-455. doi:10.1016/j.ajhg.2019.07.011

Basha M, Demeer B, Revencu N, Helaers R, Theys S, Bou Saba S, Boute O, Devauchelle B, Francois G, Bayet B, et al. 2018. Whole exome sequencing identifies mutations in $10 \%$ of patients with familial non-syndromic 
cleft lip and/or palate in genes mutated in well-known syndromes. J Med Genet 55: 449-458. doi:10.1136/ jmedgenet-2017-105110

Boycott KM, Hartley T, Biesecker LG, Gibbs RA, Innes AM, Riess O, Belmont J, Dunwoodie SL, Jojic N, Lassmann T, et al. 2019. A diagnosis for all rare genetic diseases: the horizon and the next frontiers. Cell 177: 32-37. doi:10.1016/j.cell.2019.02.040

Boyle B, Addor MC, Arriola L, Barisic I, Bianchi F, Csáky-Szunyogh M, de Walle HEK, Dias CM, Draper E, Gatt $M$, et al. 2018. Estimating global burden of disease due to congenital anomaly: an analysis of European data. Arch Dis Child Fetal Neonatal Ed 103: F22-F28. doi:10.1136/archdischild-2016-311845

Centers for Disease Control and Prevention. 2008. Update on overall prevalence of major birth defectsAtlanta, Georgia, 1978-2005. MMWR Morb Mortal Wkly Rep 57: 1-5.

Centers for Disease Control and Prevention. 2015. "1.4 Congenital anomalies—definitions." https://www.cdc .gov/ncbddd/birthdefects/surveillancemanual/chapters/chapter-1/chapter1-4.html. Retrieved 10/4/2018.

Deciphering Developmental Disorders Study. 2015. Large-scale discovery of novel genetic causes of developmental disorders. Nature 519: 223-228. doi:10.1038/nature14135

Gray KJ, Wilkins-Haug LE, Herrig NJ, Vora NL. 2019. Fetal phenotypes emerge as genetic technologies become robust. Prenat Diagn 39: 811-817. doi:10.1002/pd.5532

Gubbels CS, VanNoy GE, Madden JA, Copenheaver D, Yang S, Wojcik MH, Gold NB, Genetti CA, Stoler J, Parad RB, et al. 2020. Prospective, phenotype-driven selection of critically ill neonates for rapid exome sequencing is associated with high diagnostic yield. Genet Med 22: 736-744. doi:10.1038/s41436-0190708-6

Heinke D, Nestoridi E, Hernandez-Diaz S, Williams PL, Rich-Edwards JW, Lin AE, Van Bennekom CM, Mitchell AA, Nembhard WN, Fretts RC, et al. 2020. Risk of stillbirth for fetuses with specific birth defects. Obstet Gynecol 135: 133-140. doi:10.1097/AOG.0000000000003614

Hobbs CA, Chowdhury S, Cleves MA, Erickson S, MacLeod SL, Shaw GM, Shete S, Witte JS, Tycko B. 2014. Genetic epidemiology and nonsyndromic structural birth defects: from candidate genes to epigenetics. JAMA Pediatr 168: 371-377. doi:10.1001/jamapediatrics.2013.4858

Holmes LB, Westgate MN. 2012. Using ICD-9 codes to establish prevalence of malformations in newborn infants. Birth Defects Res A Clin Mol Teratol 94: 208-214. doi:10.1002/bdra.23001

Holmes LB, Nasri H, Beroukhim R, Hunt AT, Roberts DJ, Toufaily MH, Westgate MN. 2018. Stillborn infants: associated malformations. Birth Defects Res 110: 114-121. doi:10.1002/bdr2.1097

Jenkins MM, Almli LM, Pangilinan F, Chong JX, Blue EE, Shapira SK, White J, McGoldrick D, Smith JD, Mullikin $J C$, et al. 2019. Exome sequencing of family trios from the national birth defects prevention study: tapping into a rich resource of genetic and environmental data. Birth Defects Res 111: 1618-1632. doi:10.1002/ bdr2.1554

Kirby RS. 2017. The prevalence of selected major birth defects in the United States. Semin Perinatol 41: 338344. doi:10.1053/j.semperi.2017.07.004

Lammer EJ, Chen DT, Hoar RM, Agnish ND, Benke PJ, Braun JT, Curry CJ, Fernhoff PM, Grix A, Wand Lott IT. 1985. Retinoic acid embryopathy. N Engl J Med 313: 837-841. doi:10.1056/NEJM198510033131401

Lenke RR, Levy HL. 1980. Maternal phenylketonuria and hyperphenylalaninemia. An international survey of the outcome of untreated and treated pregnancies. N Engl J Med 303: 1202-1208. doi:10.1056/ NEJM198011203032104

Li AH, Hanchard NA, Furthner D, Fernbach S, Azamian M, Nicosia A, Rosenfeld J, Muzny D, D'Alessandro LCA, Morris $S$, et al. 2017. Whole exome sequencing in 342 congenital cardiac left sided lesion cases reveals extensive genetic heterogeneity and complex inheritance patterns. Genome Med 9: 95. doi:10.1186/ s13073-017-0482-5

Lim JS, Kim WI, Kang HC, Kim SH, Park AH, Park EK, Cho YW, Kim S, Kim HM, Kim JA, et al. 2015. Brain somatic mutations in MTOR cause focal cortical dysplasia type II leading to intractable epilepsy. Nat Med 21: 395400. doi:10.1038/nm.3824

Lin AE, Rasmussen SA, Scheuerle A, Stevenson RE. 2009. Clinical geneticists in birth defects surveillance and epidemiology research programs: past, present and future roles. Birth Defects Res A Clin Mol Teratol 85: 69-75. doi:10.1002/bdra.20548

Lionel AC, Costain G, Monfared N, Walker S, Reuter MS, Hosseini SM, Thiruvahindrapuram B, Merico D, Jobling R, Nalpathamkalam T, et al. 2018. Improved diagnostic yield compared with targeted gene sequencing panels suggests a role for whole-genome sequencing as a first-tier genetic test. Genet Med 20: 435-443. doi:10.1038/gim.2017.119

Lord J, McMullan DJ, Eberhardt RY, Rinck G, Hamilton SJ, Quinlan-Jones E, Prigmore E, Keelagher R, Best SK, Carey GK, et al. 2019. Prenatal exome sequencing analysis in fetal structural anomalies detected by ultrasonography (PAGE): a cohort study. Lancet 393: 747-757. doi:10.1016/S0140-6736(18)31940-8

Mai CT, Isenburg JL, Canfield MA, Meyer RE, Correa A, Alverson CJ, Lupo PJ, Riehle-Colarusso T, Cho SJ, Aggarwal D, et al. 2019. National population-based estimates for major birth defects, 2010-2014. Birth Defects Res 111: 1420-1435. doi:10.1002/bdr2.1589 
Meng L, Pammi M, Saronwala A, Magoulas P, Ghazi AR, Vetrini F, Zhang J, He W, Dharmadhikari AV, Qu C, et al. 2017. Use of exome sequencing for infants in intensive care units: ascertainment of severe singlegene disorders and effect on medical management. JAMA Pediatr 171: e173438. doi:10.1001/jamapedi atrics.2017.3438

Miller DT, Adam MP, Aradhya S, Biesecker LG, Brothman AR, Carter NP, Church DM, Crolla JA, Eichler EE, Epstein CJ, et al. 2010. Consensus statement: chromosomal microarray is a first-tier clinical diagnostic test for individuals with developmental disabilities or congenital anomalies. Am J Hum Genet 86: 749764. doi:10.1016/j.ajhg.2010.04.006

Miller KA, Twigg SR, McGowan SJ, Phipps JM, Fenwick AL, Johnson D, Wall SA, Noons P, Rees KE, Tidey EA, et al. 2017. Diagnostic value of exome and whole genome sequencing in craniosynostosis. J Med Genet 54: 260-268. doi:10.1136/jmedgenet-2016-104215

Nasri HZ, Houde Ng K, Westgate MN, Hunt AT, Holmes LB. 2018. Malformations among infants of mothers with insulin-dependent diabetes: is there a recognizable pattern of abnormalities? Birth Defects Res 110: 108-113. doi:10.1002/bdr2.1155

Nelson K, Holmes LB. 1989. Malformations due to presumed spontaneous mutations in newborn infants. $N$ Engl J Med 320: 19-23. doi:10.1056/NEJM198901053200104

Pehlivan D, Bayram Y, Gunes N, Coban Akdemir Z, Shukla A, Bierhals T, Tabakci B, Sahin Y, Gezdirici A, Fatih JM. 2019. The genomics of arthrogryposis, a complex trait: candidate genes and further evidence for oligogenic inheritance. Am J Hum Genet 105: 132-150. doi:10.1016/j.ajhg.2019.05.015

Perenthaler E, Yousefi S, Niggl E, Barakat TS. 2019. Beyond the exome: the non-coding genome and enhancers in neurodevelopmental disorders and malformations of cortical development. Front Cell Neurosci 13: 352. doi:10.3389/fncel.2019.00352

Petrovski S, Aggarwal V, Giordano JL, Stosic M, Wou K, Bier L, Spiegel E, Brennan K, Stong N, Jobanputra V, et al. 2019. Whole-exome sequencing in the evaluation of fetal structural anomalies: a prospective cohort study. Lancet 393: 758-767. doi:10.1016/S0140-6736(18)32042-7

Posey JE, O'Donnell-Luria AH, Chong JX, Harel T, Jhangiani SN, Coban Akdemir ZH, Buyske Z, Pehlivan D Carvalho CMB, Baxter S, et al. 2019. Insights into genetics, human biology and disease gleaned from family based genomic studies. Genet Med 21: 798-812. doi:10.1038/s41436-018-0408-7

Quinlan-Jones E, Lord J, Williams D, Hamilton S, Marton T, Eberhardt RY, Rinck G, Prigmore E, Keelagher R, McMullan DJ. 2019. Molecular autopsy by trio exome sequencing (ES) and postmortem examination in fetuses and neonates with prenatally identified structural anomalies. Genet Med 21: 1065-1073. doi:10 .1038/s41436-018-0298-8

Ramoni RB, Mulvihill JJ, Adams DR, Allard P, Ashley EA, Bernstein JA, Gahl WA, Hamid R, Loscalzo J, McCray AT, et al. 2017. The undiagnosed diseases network: accelerating discovery about health and disease. Am J Hum Genet 100: 185-192. doi:10.1016/j.ajhg.2017.01.006

Rasmussen SA, Jamieson DJ, Honein MA, Petersen LR. 2016. Zika virus and birth defects-reviewing the evidence for causality. N Engl J Med 374: 1981-1987. doi:10.1056/NEJMsr1604338

Reefhuis J, Gilboa SM, Anderka M, Browne ML, Feldkamp ML, Hobbs CA, Jenkins MM, Langlois PH, Newsome KB, Olshan AF, et al. 2015. The national birth defects prevention study: a review of the methods. Birth Defects Res A Clin Mol Teratol 103: 656-669. doi:10.1002/bdra.23384

Richards S, Aziz N, Bale S, Bick D, Das S, Gastier-Foster J, Grody WW, Hegde M, Lyon E, Spector E, et al. 2015. Standards and guidelines for the interpretation of sequence variants: a joint consensus recommendation of the American College of Medical Genetics and Genomics and the Association for Molecular Pathology. Genet Med 17: 405-424. doi:10.1038/gim.2015.30

Richter F, Morton SU, Kim SW, Kitaygorodsky A, Wasson L, Chen KM, Zhou J, Qi H, Patel N, DePalma S, et al. 2020. Role of noncoding de novo variants in congenital heart disease. Nat Genet 52: 769-777. doi:10 .1038/s41588-020-0652-z

Ross ME, Mason CE, Finnell RH. 2017. Genomic approaches to the assessment of human spina bifida risk. Birth Defects Res 109: 120-128. doi:10.1002/bdra.23592

Salinas-Torres VM, Gallardo-Blanco HL, Salinas-Torres RA, Cerda-Flores RM, Lugo-Trampe JJ, VillarrealMartínez DZ, Ibarra-Ramírez M, Martínez de Villarreal LE. 2020. Whole exome sequencing identifies multiple novel candidate genes in familial gastroschisis. Mol Genet Genomic Med 8: e1176. doi:10.1002/ mgg3.1176

Sawyer SL, Hartley T, Dyment DA, Beaulieu CL, Schwartzentruber J, Smith A, Bedford HM, Bernard G, Bernier FP, Brais B, et al. 2016. Utility of whole-exome sequencing for those near the end of the diagnostic odyssey: time to address gaps in care. Clin Genet 89: 275-284. doi:10.1111/cge.12654

Shamseldin HE, Kurdi W, Almusafri F, Alnemer M, Alkaff A, Zeneb B, Alhashem A, Tulbah M, Alsahan N, Khan $\mathrm{R}$, et al. 2018. Molecular autopsy in maternal-fetal medicine. Genet Med 20: 420-427. doi:10.1038/gim .2017 .111 
Shi H, Enriquez A, Rapadas M, Martin EMMA, Wang R, Moreau J, Lim CK, Szot JO, Ip E, Hughes JN, et al. 2017. NAD deficiency, congenital malformations, and niacin supplementation. N Engl J Med 377: 544-552. doi:10.1056/NEJMoa1616361

Sifrim A, Hitz MP, Wilsdon A, Breckpot J, Al Turki SH, Thienpont B, McRae J, Fitzgerald TW, Singh T, Swaminathan GJ, et al. 2016. Distinct genetic architectures for syndromic and nonsyndromic congenital heart defects identified by exome sequencing. Nat Genet 48: 1060-1065. doi:10.1038/ng.3627

Springett A, Wellesley D, Greenlees R, Loane M, Addor MC, Arriola L, Bergman J, Cavero-Carbonell C, CsakySzunyogh M, Draper ES, et al. 2015. Congenital anomalies associated with trisomy 18 or trisomy 13: a registry-based study in 16 European countries, 2000-2011. Am J Med Genet A 167A: 3062-3069. doi:10 .1002/ajmg.a.37355

Stoll C, Dott B, Alembik Y, Roth MP. 2015. Associated congenital anomalies among cases with down syndrome. Eur J Med Genet 58: 674-680. doi:10.1016/j.ejmg.2015.11.003

Straub L, Huybrechts KF, Bateman BT, Mogun H, Gray KJ, Holmes LB, Hernandez-Diaz S. 2019. The impact of technology on the diagnosis of congenital malformations. Am J Epidemiol 188: 1892-1901. doi:10.1093/ aje/kwz153

Timberlake AT, Choi J, Zaidi S, Lu Q, Nelson-Williams C, Brooks ED, Bilguvar K, Tikhonova I, Mane S, Yang JF. 2016. Two locus inheritance of non-syndromic midline craniosynostosis via rare rare SMAD6 and common BMP2 alleles. Elife 5: e20125. doi:10.7554/eLife.20125

Toufaily MH, Westgate MN, Lin AE, Holmes LB. 2018. Causes of congenital malformations. Birth Defects Res 110: 87-91. doi:10.1002/bdr2.1105

van der Ven AT, Connaughton DM, Ityel H, Mann N, Nakayama M, Chen J, Vivante A, Hwang DY, Schulz J, Braun DA, et al. 2018. Whole-exome sequencing identifies causative mutations in families with congenital anomalies of the kidney and urinary tract. J Am Soc Nephrol 29: 2348-2361. doi:10.1681/ASN .2017121265

Vora NL, Powell B, Brandt A, Strande N, Hardisty E, Gilmore K, Foreman AKM, Wilhelmsen K, Bizon C, Reilly J, et al. 2017. Prenatal exome sequencing in anomalous fetuses: new opportunities and challenges. Genet Med 19: 1207-1216. doi:10.1038/gim.2017.33

Wapner RJ, Martin CL, Levy B, Ballif BC, Eng CM, Zachary JM, Savage M, Platt LD, Saltzman D, Grobman WA et al. 2012. Chromosomal microarray versus karyotyping for prenatal diagnosis. N Engl J Med 367: 21752184. doi:10.1056/NEJMoa1203382

Wojcik MH, Schwartz TS, Thiele KE, Paterson H, Stadelmaier R, Mullen TE, VanNoy GE, Genetti CA, Madden JA, Gubbels CS, et al. 2019. Infant mortality: the contribution of genetic disorders. J Perinatol 39: 16111619. doi:10.1038/s41372-019-0451-5

Williams J, Mai CT, Mulinare J, Isenburg J, Flood TJ, Ethen M, Frohnert B, Kirby RS, Centers for Disease Control and Prevention. 2015. Updated estimates of neural tube defects prevented by mandatory folic acid fortification-United States, 1995-2011. MMWR Morb Mortal Wkly Rep 64: 1-5.

Xu JQ, Murphy S, Kochanek KD, Arias E. 2020. Mortality in the United States, 2018. NCHS Data Brief, no 355. National Center for Health Statistics, Hyattsville, MD. 


\title{
COLD SPRING HARBOR Molecular Case Studies
}

\section{Deciphering congenital anomalies for the next generation}

\author{
Monica H. Wojcik and Pankaj B. Agrawal
}

Cold Spring Harb Mol Case Stud 2020, 6: a005504 originally published online August 21, 2020 Access the most recent version at doi: $10.1101 / \mathrm{mcs} .0005504$

References This article cites 55 articles, 4 of which can be accessed free at: http://molecularcasestudies.cshlp.org/content/6/5/a005504.full.html\#ref-list-1

License This article is distributed under the terms of the Creative Commons Attribution-NonCommercial License, which permits reuse and redistribution, except for commercial purposes, provided that the original author and source are credited.

Email Alerting Receive free email alerts when new articles cite this article - sign up in the box at the Service top right corner of the article or click here. 